\title{
Clytini neotropicais II (Coleoptera, Cerambycidae, Cerambycinae)
}

\author{
Ubirajara R. Martins ${ }^{1,3} \&$ Maria Helena M. Galileo ${ }^{2,3}$
}

\begin{abstract}
${ }^{1}$ Museu de Zoologia, Universidade de São Paulo. Caixa Postal 42494, 04218-970 São Paulo-SP, Brasil.
${ }^{2}$ Museu de Ciências Naturais, Fundação Zoobotânica do Rio Grande do Sul. Caixa Postal 1188, 90001-970 Porto Alegre-RS, Brasil. ${ }^{3}$ Pesquisador do $\mathrm{CNPq}$
\end{abstract}

\begin{abstract}
Neotropical Clytini II (Coleoptera, Cerambycidae, Cerambycinae). New species described and figured: Megacyllene (M.) nevermanni sp. nov. from Costa Rica (Limón); M. (M.) punensis sp. nov. from Peru (Puno); Neoclytus fraterculus sp. nov. from Venezuela (Guárico); N. zonatus from Guatemala (Alta Verapaz); N. vitellinus sp. nov. from Costa Rica (Guanacaste); Mecometopus erratus sp. nov. from Colombia (Boyacá); M. latithorax sp. nov. from Panama (Panama).
\end{abstract}

KEYWORDS. Mecometopus; Megacyllene; Neoclytus; new species; taxonomy.

RESUMO. Clytini neotropicais II (Coleoptera, Cerambycidae, Cerambycinae). Novas espécies são descritas e figuradas: Megacyllene (M.) nevermanni sp. nov. da Costa Rica (Limón); M. (M.) punensis sp. nov. do Peru (Puno); Neoclytus fraterculus sp. nov. da Venezuela (Guárico); N. zonatus da Guatemala (Alta Verapaz); N. vitellinus sp. nov. da Costa Rica (Guanacaste); Mecometopus erratus sp. nov. da Colômbia (Boyacá); M. latithorax sp. nov. do Panamá (Panamá).

PALAVRAS-CHAVE. Mecometopus; Megacyllene; Neoclytus; espécies novas; taxonomia.

Baseados em material recebido principalmente do National Museum of Natural History, Washington (USNM), descrevemos sete espécies em Clytini, das Américas Central e do Sul, nos gêneros Mecometopus Thomson, 1860, Megacyllene (Megacyllene) Casey, 1912 e Neoclytus Thomson, 1860.

Recentemente, Monné \& Napp (2004) estudaram espécies de Megacyllene, Napp \& Monné (2006) as do gênero Mecometopus e Di Iorio (2006) tratou dos Clytini da América do Sul. Ora apresentamos um novo estudo dos Clytini que acrescentam espécies aquelas descritas por Galileo \& Martins (2007).

As siglas utilizadas no texto correspondem às instituições: Instituto Nacional de Biodiversidad, Santo Domingo de Heredia (INBIO); Museu de Ciências Naturais, Fundação Zoobotânica do Rio Grande do Sul, Porto Alegre (MCNZ); Museu de Zoologia, Universidade de São Paulo, São Paulo (MZSP).

\section{Megacyllene (M.) nevermanni sp. nov.}

(Fig. 1)

Etimologia. O nome específico é uma homenagem póstuma a F. Nevermann, entomólogo costaricence.

Tegumento corporal preto. Fronte com carena bifurcada. Occipício com faixa transversal de pubescência amarelada. Protórax com três faixas transversas de pubescência amarelada. Élitros com as faixas de pubescência: (1) branco e amarelada, oblíqua do escutelo para trás dos ângulos umerais, no sexto basal; (2) branco e amarelada, em "V" com o vértice iniciado no escutelo; (3) branco e amarelada, em "V" com o ramo interno prolongado junto à sutura até a faixa dois; (4) branca, curta, ao lado da mancha sutural, no terço apical, oblíqua em sentido descendente da sutura para a margem; (5) mancha branca na região apical. Último urotergito com mancha de pubescência amarelada ou esbranquiçada.

Face ventral com mancha de pubescência: (1) branca e amarelada nos mesepisternos; (2) branca, mais esparsa, na parte anterior do metepisterno; (3) branca no terço posterior do metepisterno; (4) no metasterno, branca na base e escassa no ápice; (5) branco-amarelada nos lados dos urosternitos I e II.

Dimensões em mm, macho/fêmea respectivamente. Comprimento total, 11,2-13,4/ 10,6-14,9; comprimento do élitro, 7,9-9,6/7,2-10,9; largura umeral, 3,5-4,3/3,5-5,0.

Material-tipo. Holótipo macho, COSTA RICA, Limón, Reventazon (Hamburg Farm) 15.VI.1924, F. Nevermann col. (USNM). Parátipos: ditto, fêmea, 15.VIII.1923, F. Nevermann col. (em tronco de Inga sp.) (USNM); 2 machos, 2 fêmeas, 15.VI.1924, F. Nevermann col. (macho e fêmea, MZSP; macho, MCNZ, fêmea, USNM); macho, 13.III.1925, F. Nevermann col. (USNM); macho, 4.VI.1929, F. Nevermann col. (USNM); macho, 28.XI.1935, F. Nevermann col. (USNM); Limón: La Colônia (23 km NE de Guapiles) macho, 21.VIII.1966, R. D. Sopé col. (USNM); Limón: Cahuita (2 milhas S, "rain forest"), macho, 24.V.1998, A. S. Menke col. (USNM).

Discussão. Megacyllene (M.) nevermanni sp. nov., é morfologicamente muito semelhante a Megacyllene $(M$. angulata (Fabricius, 1775), mas difere pelo ápice dos élitros 
com pequena mancha de pubescência branca; terço apical dos élitros com a faixa interrompida ao lado da mancha sutural, branca e lados do urosternito III sem mancha de pubescência. Em $M$. (M.) angulata, o ápice dos élitros tem faixa de pubescência amarela em forma de "V" invertido e um dos ramos percorre a sutura até a extremidade e os lados do urosternito III têm mancha de pubescência branca.

\section{Megacyllene (M.) punensis sp. nov.}

(Fig. 2)

Etimologia. O epíteto refere-se a Puno, província peruana.

Tegumento preto. Fronte com projeção em "Y" e alguma pubescência esbranquiçada na parte inferior. Pilosidade esbranquiçada, esparsa, nas genas e atrás dos olhos. Antenas com tegumento preto e pubescência acinzentada.

Protórax com os lados angulosos perto da base. Pronoto com duas faixas de pubescência amarelada: uma transversal, próximo à margem anterior; outra, transversa e curva no meio. Partes laterais do protórax com mancha de pubescência esbranquiçada próxima ao proepimero.

Cada élitro com cinco faixas de pubescência amarelada: (1) transversal, basal, do escutelo ao úmero; (2) curva, no meio da metade anterior; (3) transversal, no meio; (4) levemente curva no terço apical; (5) transversal, adiante do ápice. Extremidades elitrais aguçadas.

Face ventral com faixa de pubescência amarelada na borda apical dos urosternitos I a IV. Num dos machos, com manchas de pubescência esbranquiçada: no processo intercoxal do metasterno; (2) nos lados, adiante das metacoxas; (3) anterior e posteriormente nos metepisternos.

Dimensões em mm, macho/fêmea respectivamente. Comprimento total, 13,6-13,8/16,2; comprimento do protórax, 3,1-3,3/3,7; maior largura do protórax, 3,8-3,9/4,4; comprimento do élitro, 9,5-9,8/11,5; largura umeral, 3,9-4,3/5,5.

Material-tipo. Holótipo macho, PERU, Puno: Puno (4000 m), 24.VI.1941, J. Soukup col., lote 41-13260 (USNM). Parátipos: mesmos dados do holótipo, macho (MZSP); fêmea (USNM).

Discussão. Megacyllene (M.) punensis sp. nov. caracterizase pelo pronoto com apenas duas faixas transversais de pubescência amarelada uma junto à orla anterior e outra central.

\section{Neoclytus fraterculus sp. nov.} (Fig. 3)

Etimologia. Latim, fraterculus $=$ irmãozinho, assemelharse como irmão, alusivo à semelhança com $N$. pusillus (Laporte \& Gory, 1835).

Tegumento corporal avermelhado. Fronte coberta por pubescência esbranquiçada. Mancha de pubescência amarelada atrás dos olhos.

Protórax com duas faixas transversais de pubescência amarelada junto às margens anterior e posterior. Pronoto revestido por pubescência esbranquiçada e esparsa, com três faixas de grânulos: uma central e uma a cada lado. Prosterno recoberto por pubescência branca.

Élitros com pubescência esbranquiçada da base ao meio. Cada élitro com três áreas de pubescência mais densa: (1) branca, iniciada atrás do escutelo até adiante do meio, corre paralela a sutura e alargada gradualmente para o lado externo; (2) branca, no meio, transversal, projetada para a frente em pequena extensão junto à sutura (perto da sutura a pubescência é mais amarelada); (3) mancha sutural, branco-amarelada, triangular, no quarto apical. Extremidades elitrais com dois espinhos: o externo pouco mais longo do que o sutural.

Face ventral com pubescência esbranquiçada, esparsa; pubescência mais concentrada e branco-amarelada na parte apical do mesepisterno, no terço apical do metepisterno, no processo mesosternal, faixa atrás da mesocoxas e nos lados do metasterno. Urosternitos I e II com pubescência brancoamarelada na metade apical.

Pernas revestidas por pubescência amarelada, esparsa. Ápice dos metafêmures com espinhos curtos.

Dimensões em mm, macho. Comprimento total, 8,9-10,0; comprimento do protórax, 2,5-2,7; maior largura do protórax, 2,4-2,7; comprimento do élitro, 5,8-6,7; largura umeral, 2,4-2,7.

Material-tipo. Holótipo macho, VENEZUELA, Guárico: Hato Massaguaral (45 km S Calabozo, 75 m, "Galery Forest", luz ultravioleta), 23-24.1V.1988, M. Epstein \& R. Blahnik col. (USNM).

Parátipos. Ditto, macho, 3-10.V.1985, Mencke \& Carpenter col. (USNM); ditto, macho, 11-19.V.1985, Mencke \& Carpenter col. (MZSP)

Discussão. Neoclytus fraterculus sp. nov. é muito semelhante a N. pusillus (Laporte \& Gory, 1838) e difere pela pubescência esbranquiçada que cobre toda metade anterior dos élitros. Em $N$. pusillus a pubescência nunca atinge a primeira faixa dos élitros. Uma outra espécie, $N$. tapajonus Bates, 1870, da Hiléia, tem o mesmo padrão e, muito provavelmente, é sinônima de $N$. pusillus.

\section{Neoclytus zonatus sp. nov.}

(Fig. 4)

Etimologia. Latim, zonatus = marcado com listras coloridas, alusivo ao padrão da pubescência do pronoto.

Cabeça com tegumento castanho. Fronte com duas faixas de pubescência densa, amarelada, bordejada externamente por pubescência branca. Faixa amarelada atrás do olhos, das genas até o occipício. Antenas castanho-avermelhadas. Gula com longos pêlos esbranquiçados e densos.

Protórax com gibosidade arredondada nos lados. Pronoto castanho com faixas de pubescência amarelada: (1) muito próxima da orla anterior, interrompida no centro, alargada nas partes laterais do protórax; (2) na depressão basal, interrompida 
no meio; (3) duas faixas longitudinais a cada lado do disco. Partes laterais do protórax com mancha triangular, amarelada, no centro e faixa em continuação daquela da depressão basal do pronoto. Prosterno com tegumento alaranjado e coberto por pubescência amarelada intercalado por longos pêlos esbranquiçados. Escutelo com bordas laterais cobertas por pubescência amarela, densa.

Élitros com sexto basal alaranjado e acastanhado no restante da superfície. Três faixas de pubescência amarelada, densa, oblíquas em sentido descendente da sutura para a margem: uma no sexto anterior; outra no quarto anterior, a terceira, pouco mais alargada que as demais, no meio e prolongada, estreitamente, pela sutura até a segunda faixa. No quarto apical dos élitros, quarta faixa de pubescência amarelada, mais estreita e transversal, ligeiramente curva para o lado da margem. Extremidades elitrais truncadas e desarmadas.

Face ventral do corpo com pubescência amarelada no metasterno, na parte interna dos metepisternos e no ápice dos quatro primeiros urosternitos. Último urotergito profundamente entalhado no centro.

Dimensões em mm, holótipo fêmea. Comprimento total, 13,7; comprimento do protórax, 3,2; maior largura do protórax, 3.,7; comprimento do élitro, 9,7; largura umeral, 3,9.

Material-tipo. Holótipo fêmea, GUATEMALA, Alta Verapaz: Panzos, sem outros dados (USNM).

Discussão. Neoclytus zonatus sp. nov. pode ser comparada com N. aulai Bruch, 1911, N. beltianus Bates, 1885, N. ictericus (Gounelle, 1911) e N. pinima Galileo \& Martins, 2007 por apresentar faixas de pubescência amarelada no pronoto. Separa-se de $N$. aulai, $N$. beltianus e $N$. ictericus por apresentar gibosidade nos lados do protórax. $N$. zonatus separase de $N$. pinima pelo padrão de colorido do pronoto e pelas faixas de pubescência amarelada na base dos élitros menos oblíquas, a primeira não toca a base, a segunda está interligada pela sutura com a terceira.

\section{Neoclytus vitellinus sp. nov.}

(Fig. 5)

Etimologia, Latim, vitellinus = cor da gema do ovo, alusivo à coloração das faixas elitrais.

Cabeça com tegumento castanho-escuro. Lados da fronte com duas faixas longitudinais de pubescência amarelada; faixa amarelada transversal do occipício até a faixa inferior passando atrás dos olhos. Antenas avermelhadas (macho) ou avermelhadas até a metade basal do $\mathrm{V}$ e, a partir da metade apical do V até XI, acastanhados na face superior (fêmea). Pernas avermelhadas.

Protórax com tegumento castanho e faixas de pubescência amarela: (1) transversal próxima da orla anterior; (2) sobre a depressão basal, alargada para os lados do protórax; (3) em forma de "V" a cada lado do meio do pronoto. Região entre as faixas em "V" com asperezas. Prosterno com pubescência amarelada. Escutelo revestido por pubescência amarelada, densa.

Élitros com tegumento castanho-avermelhado e faixas de pubescência amarelada: (1) curta, junto à base, que não toca a sutura ou a margem; (2) oblíqua em sentido descendente da sutura para a margem, inicia-se próximo do escutelo e estendese até a margem no terço anterior; (3) levemente oblíqua, no mesmo sentido da anterior, no meio, um pouco projetada para adiante junto da sutura; (4) no terço apical, com a margem posterior transversal e a margem anterior oblíqua no mesmo sentido; (5) envolve os ápices. No macho, as faixas são mais largas. Extremidades elitrais obliquamente truncadas e com espículo externo.

Face ventral com pubescência amarelada nos esternos meso- e metatorácicos (menos no centro do metasterno) e largamente nos urosternitos.

Dimensões em mm, macho/fêmea. Comprimento total, 10,5/ 10,2; comprimento do protórax, 3,3/3,1; maior largura do protórax, 2,8/2,7; comprimento do élitro, 6,8/6,7; largura umeral, $3,0 / 3,1$.

Material-tipo. Holótipo macho, COSTA RICA, Guanacaste: Los Almendros (Parque Nacional Guanacaste), 12-31.V.1993, E. López col., L_N,_334900_339800 (INBIO).

Parátipos:, Guanacaste: Estación Maritza (600 m), fêmea, 27.II a 10.III.1992, III Curso Biodiversidad col., L-_N e L_M_326500_372600\#2278 (INBIO); Estación Los Almendros (300 m), macho, 1-22.IV.1995, E. E. Lopez, L_N_334850_339500\#4789 (MZSP).

Discussão. A pubescência do pronoto organizada em faixas amareladas conduz $N$. vitellinus sp. nov. ao grupo de espécies: N. aulai Bruch, 1911, N. beltianus Bates, 1885, N. ictericus (Gounelle, 1911), N. viticollis Aurivillius, 1920 e N. pinima Galileo \& Martins, 2007, mas difere de todas pela organização das faixas de pubescência amarelada no pronoto.

Distingue-se de $N$. vitticollis, do Peru, por apresentar cinco faixas de pubescência amarelada nos élitros, em $N$. vitticollis existem quatro faixas. De $N$. zonatus sp. nov, separa-se pelo padrão das faixas elitrais, além disso, $N$. vitellinus não tem gibosidade nos lados do protórax.

\section{Mecometopus erratus sp. nov.}

(Fig. 6)

Etimologia. Latim, erratus = erro, alusivo a erro de identificação.

Tegumento corporal preto, exceto antenas, élitros e pernas com tegumento avermelhado. Fronte com duas faixas de pubescência amarelada. Antenas avermelhadas na base e mais acastanhadas para a extremidade; atingem a base dos élitros.

Protórax com faixa transversal na depressão basal de pubescência amarelada. Pronoto regularmente convexo, fina e densamente pontuado (40X). 

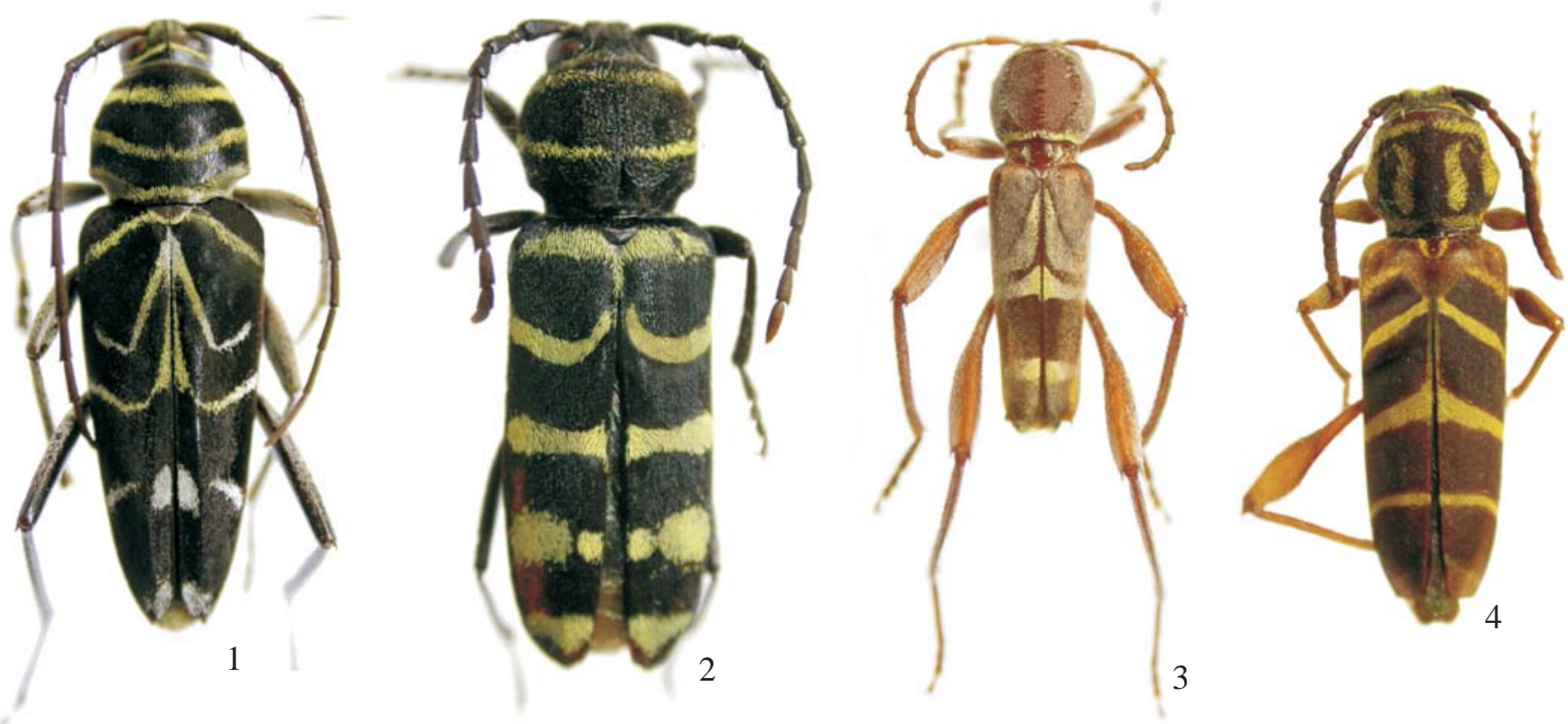

Figs. 1-4. Habitus. 1, Megacyllene (M.) nevermanni sp. nov., holótipo macho, comprimento 13,5 mm; 2, Megacyllene (M.) punensis sp. nov., holótipo macho, comprimento $13,8 \mathrm{~mm} ; 3$, Neoclytus fraterculus sp. nov., holótipo macho, comprimento, 10,9 mm; 4, Neoclytus zonatus sp. nov., holótipo macho, comprimento $13,7 \mathrm{~mm}$.

Cada élitro com três faixas de pubescência amarelada: (1) no terço anterior, oblíqua da sutura para a margem; (2) oblíqua, no mesmo sentido, no meio; (3) transversal, no terço apical. Extremidades elitrais com espículo no lado externo.

Face ventral com manchas de pubescência esbranquiçada: nos mesepisternos, na parte posterior dos metepisternos, adiante das metacoxas e nos urosternitos I a IV.

Dimensões em mm, macho/fêmea. Comprimento total, 9,5/
8,1; comprimento do protórax, 2,3/1,8; maior largura do protórax, 2,3/2,0; comprimento do élitro, 6,8/6,0; largura umeral, 2,8/2,3.

Material-tipo. Holótipo macho. COLÔMBIA, Boyacá: Iguaque (Cabana Mamaranos, 5⒉ $5^{\prime} \mathrm{N}, 7^{\circ} 27^{\prime} \mathrm{W}, 2855 \mathrm{~m}$ ) 30.VII-17.VIII.2000, P. Reina col., Malaise (MZSP). Parátipos: ditto, (Quebrada Los Francos, $\left.5^{\circ} 25^{\prime} \mathrm{N}, 73^{\circ} 27^{\prime} \mathrm{W}, 2860 \mathrm{~m}\right)$, macho, 7-24.II.2001, P. Reina col., Malaise (MCNZ); ditto, (La Planada, $5^{\circ} 25^{\prime} \mathrm{N}, 73^{\circ} 27^{\prime} \mathrm{W}, 2850 \mathrm{~m}$ ), fêmea, 4-21.XII.2000, P. Reina col., Malaise (MZSP).

Discussão. Diversos exemplares de Mecometopus errratus
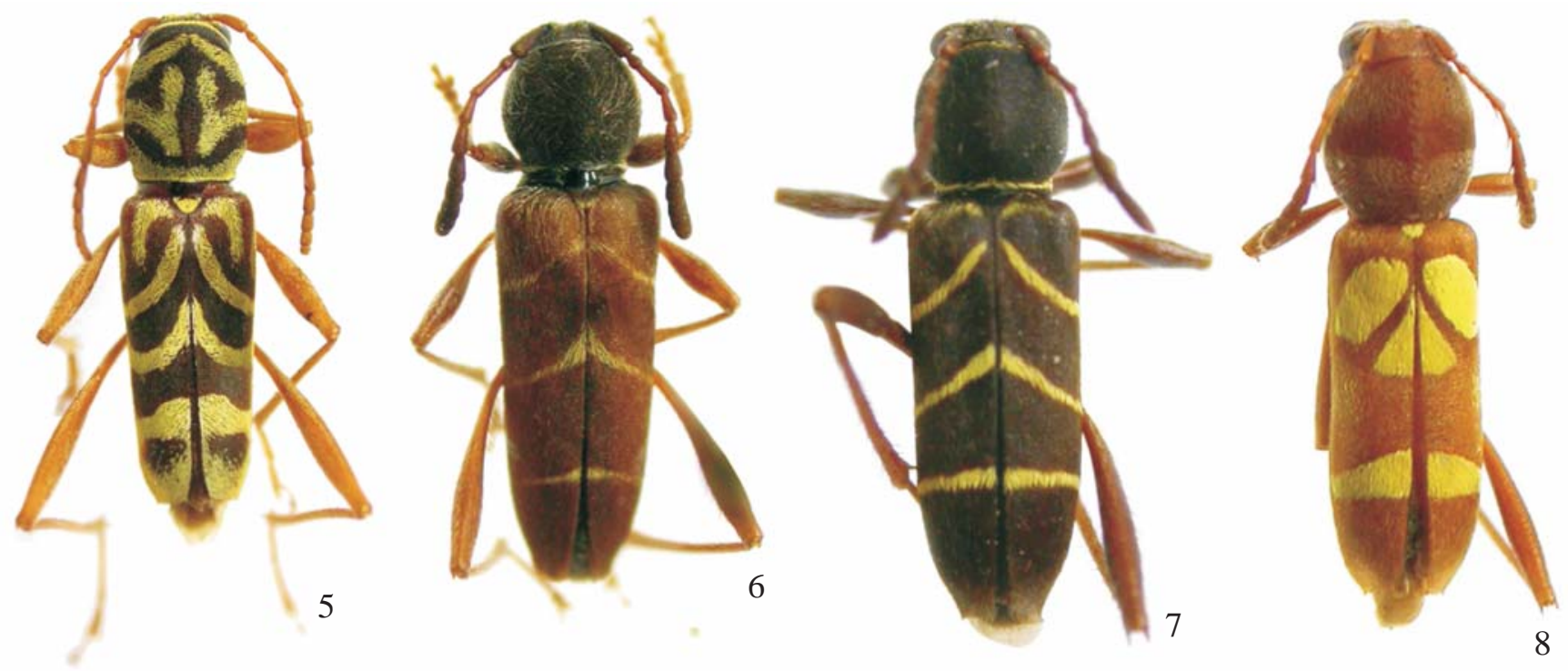

Figs. 5-8. Habitus. 5, Neoclytus vitellinus sp. nov., holótipo macho, comprimento 10,3 mm; 6, Mecometopus erratus sp. nov., holótipo macho, comprimento 6,8 mm; 7, Mecometopus quadrifasciatus (Chevrolat, 1861), comprimento 7,0 mm; 8. Mecometopus latithorax sp. nov., holótipo macho, comprimento $6,3 \mathrm{~mm}$. 
sp. nov. foram identificados erroneamente por Martins como M. quadrifasciatus (Chevrolat, 1861) e devolvidos ao Instituto Humboldt (Villa de Leiva). Recentemente examinamos o verdadeiro M. quadrifasciatus (Fig. 7) procedente da Colômbia, Valle, perto de Pichinde, (5000 pés). Mecometopus erratus $\mathbf{s p .}$ nov. distingue-se de $M$. quadrifasciatus pelos élitros avermelhados contrastantes com o colorido do tórax e da cabeça, pela ausência de faixa de pubescência amarelada junto à base dos élitros e pela presença de pubescência amarela nos urosternitos I a IV. Em M. quadrifasciatus, os élitros e o protórax são castanhos, a base dos élitros tem faixa de pubescência amarelada e apenas os urosternitos I e II possuem faixa de pubescência amarelada.

\section{Mecometopus latithorax sp. nov.}

(Fig. 8)

Etimologia . Latim, latus $=$ largo; thorax $=$ tórax, alusivo à largura do protórax.

Tegumento corporal avermelhado. Fronte mais longa do que larga, sem faixas de pubescência. Antenas inteiramente avermelhadas. Protórax com três faixas longitudinais de grânulos: uma central mais conspícua e uma a cada lado com grânulos pequenos; área ao lado da faixa central de grânulos com a superfície granulosa (50x). Partes laterais do protórax com grânulos (50x). Pubescência esbranquiçada esparsa reveste todo o protórax. Escutelo com densa pubescência amarelada.

Cada élitro com áreas de pubescência amarelada, densa: (1) elíptica, no meio da metade anterior; (2) triangular, invade a região entre a mancha elíptica; (3) faixa transversal no terço apical. Os lados do meio com pubescência amarelada, esparsa. Extremidades elitrais com espículo externo.

Face ventral com manchas de pubescência amarelada, nos machos: (1) na parte posterior do mesepisterno; (2) nos lados do metasterno; (3) no ápice do metepisterno; (4) manchas longitudinais nos urosternitos I e II. Nas fêmeas, as manchas são brancas ou bicolores; (1) branca, na parte posterior do mesepisterno; (2) a metade posterior branca e o restante amarelado no metepisterno e (3) parcialmente branca, nos lados do primeiro urosternito.

O ápice dos metafêmures ultrapassa a margem apical dos élitros.

Dimensões em mm, holótipo macho/parátipo fêmea. Comprimento total, 6,3/7,5; comprimento do protórax, 1,8/2,1; maior largura do protórax, 1,8/2,2; comprimento do élitro, 4,2/ 5,$3 ;$ largura umeral, $1,7 / 2,1$.

Material-tipo. Holótipo macho, PANAMÁ, Panamá: Barro Colorado, I-III.1944, sem nome do coletor, Z-5123 (USNM). Parátipo fêmea, PANAMÁ, Panamá: Paraíso (4 milhas SW), 21.VIII.1971, W. E. Biving col. (MZSP).

Discussão. Mecometopus latithorax sp. nov. tem padrão de colorido peculiar e protórax pouco mais largo que a largura umeral. Não fora o colorido corporal avermelhado, $M$. latithorax poderia confundir-se com M. curtus (Laporte \& Gory, 1835) do Brasil meridional, com colorido corporal acastanhado. O desenho dos élitros também é semelhante aos de M. laetus (Fabricius, 1801) e M. leprieuri (Laporte \& Gory, 1835) espécies de colorido corporal acastanhado.

Agradecimentos. A James Wappes (ACMS) e Frank T. Hovore (in memorian) pela remessa dos Clytini, respectivamente, do USNM e do INBIO; a Eleandro Moysés (MCNZ) pela execução das fotografias e tratamento digital.

\section{REFERÊNCIAS}

Di Iorio, O. R. 2006. New records, synonymies and a new species of Clytini from South America. Les cahiers Magellanes 58: 1-28.

Galileo, M. H. M. \& U. R. Martins. 2007. Contribuição ao conhecimento dos Clytini neotropicais (Coleoptera, Cerambycidae, Cerambycinae). Revista Brasileira de Entomologia 51: 346351.

Monné, M. A. \& D. S. Napp. 2004. Megacyllene Casey (Coleoptera, Cerambycidae): novas sinonímias e descrição de uma nova espécie. Revista Brasileira de Entomologia 48: 323-324.

Napp, D. S. \& M. A. Monné. 2006. Novas espécies de Mecometopus Thomson, (Coleoptera, Cerambycidae). Revista Brasileira de Entomologia 50: 39-42.

Recebido em 12/12/2007; aceito em 06/02/2008 